Archives de sciences sociales des religions

155 | juillet-septembre 2011

Le consensus des experts | Inattendus pèlerinages

\title{
Introduction: Inattendus pèlerinages
}

\section{Franck Frégosi}

\section{OpenEdition}

\section{Journals}

Édition électronique

URL : http://journals.openedition.org/assr/23322

DOI : 10.4000/assr.23322

ISBN : 978-2-7132-2303-7

ISSN : $1777-5825$

Éditeur

Éditions de l'EHESS

Édition imprimée

Date de publication : 30 septembre 2011

Pagination : 103-108

ISSN : 0335-5985

Référence électronique

Franck Frégosi, «Introduction: Inattendus pèlerinages », Archives de sciences sociales des religions [En ligne], 155 | juillet-septembre 2011, mis en ligne le 10 novembre 2011, consulté le 20 avril 2019. URL http://journals.openedition.org/assr/23322 ; DOI : 10.4000/assr.23322 


\section{Inattendus pèlerinages}





\section{Franck Frégosi}

\section{Introduction : Inattendus pèlerinages}

Il est d'usage de considérer que tout pèlerinage en tant que fait religieux se caractérise par au moins trois traits principaux. Il suppose d'abord la présence d'un lieu réputé saint vers lequel les pèlerins sont censés se rendre. Il induit ensuite le fait de se déplacer : le voyage proprement dit est effectué de façon individuelle ou collective afin d'atteindre ce lieu sacré et saint. Il est enfin un but recherché, la finalité d'une quête qui consiste en l'obtention de bienfaits spirituels, d'une grâce particulière, c'est-à-dire, en la rencontre de Dieu et/ou de bienfaits matériels, voire physiologiques, qui lui sont afférents comme la guérison.

\section{Phénoménologie du pèlerinage et la transversalité de ses lectures}

Selon l'approche phénoménologique du pèlerinage développée par Alphonse Dupront (1987), l'acte pèlerin combine nécessairement un " aller » et un " ailleurs ", un départ, un éloignement, une rupture à la fois physique et mentale avec le quotidien pour rejoindre des lieux sacrés, qui sont lieux de ressourcement pour les fidèles. Le pèlerinage est en même temps une quête humaine extraordinaire du sacral, c'est à proprement parler comme une mise à l'épreuve de sa foi et un accomplissement de celle-ci. L'acte pèlerin exprime enfin une volonté de puissance collective ou individuelle dont la recherche d'immortalité ou l'assurance d'éternité sont les principales déclinaisons. Sujet majeur pour les historiens (Boutry, Fabre, Julia, 2000 ; Dupront, 1987 ; Chélini, Branthomme, 2004), le fait pèlerin a dessiné toute une géographie et construit une architecture du sacré dont on peut aujourd'hui physiquement toujours suivre les tracés, et visiter un par un les édifices religieux qui en jalonnent les différentes étapes comme autant de balises sur le chemin d'une rencontre avec le divin. Mais le pèlerinage interpelle tout autant les sociologues et les anthropologues du religieux. Les pèlerinages se retrouvent dans l'ensemble des traditions religieuses du globe. Qu'ils aient une vocation ou une aura transnationale comme Jérusalem, Lourdes, La Mecque, ou que leur rayonnement soit régional ou local, comme le pèlerinage sikh d'Amritsar en Inde, celui de Dajija Matsu à Taïwan, ou le circuit de dévotion aux quatre-vingt-huit sanctuaires de Shikoku au Japon en mémoire de Kôbô 
Taishi, le phénomène est semblable en général. Seul change le nombre des pèlerins et la durée de leur voyage.

Pour les sciences sociales, le pèlerinage demeure un riche objet d'étude parce que cette manifestation religieuse est tout à la fois une puissante socialisation en actes et un formidable réservoir de mobilisation sociale, qui ont traversé les siècles et surmonté - en Europe (Claverie, 2003) et ailleurs (Aubin-Boltanski, 2007) -, des vicissitudes politiques multiples (régimes dictatoriaux, régimes communistes, dictatures militaires, etc.) En lui s'articulent l'individualité de l'acte premier de foi qui pousse un individu à partir, avec une scénographie spatiale et rituelle plus ou moins codifiée et respectée et enfin un "tropisme collectif de l'unité »(Dupront, 1987 : 389), l'inscription dans une extraordinaire société fraternelle, la société pèlerine, dont Émile Zola livre un témoignage paradoxal dans Lourdes (1894), où il fait du pèlerinage marial pyrénéen un récit minutieux, critique et audacieux, comparant les attentes des pèlerins devant la grotte de Massabielle à celles des socialistes de la même époque : "Si les anarchistes, les socialistes extrêmes, écrivait-il, demandaient violemment l'égalité dans la richesse, la mise en commun des jouissances de ce monde, les pèlerins réclamaient avec des larmes l'égalité dans la santé, le partage équitable de la paix morale et physique. Ceux-ci comptaient sur le miracle, les autres s'adressaient à l'action brutale. Au fond, c'était le même rêve exaspéré de fraternité et de justice, l'éternel besoin de bonheur, plus de pauvres, plus de malades, tous heureux » (Zola, 1894 : 596).

Mais les multiples déclinaisons confessionnelles (et transnationales) que sont les pèlerinages de Lourdes, de Saint-Jacques-de-Compostelle, de Fatima, de Jérusalem ou de La Mecque n'épuisent pas la richesse des situations et des formes prises par ce phénomène dans l'histoire passée et présente des sociétés humaines. Dans ce numéro des Archives de sciences sociales des religions, nous avons choisi de porter un regard plus contrasté sur le fait pèlerin en l'appréhendant au travers de recherches inédites combinant les approches ethnographiques, anthropologiques, sociologiques et historiques et se focalisant sur l'étude de pèlerinages que nous avons choisi de désigner comme inattendus. Ce dernier qualificatif veut rendre compte d'un ensemble hétérogène de pèlerinages quelque peu atypiques sinon improbables qui malmènent les clivages entre les religions et la césure entre religiosité et société séculière.

\section{Hybridation religieuse}

Relevant de diverses expressions du croire, ces pèlerinages ont en commun de transgresser les limites entre les confessions dominantes et de bousculer leurs orthodoxies respectives. Ils rendent visibles des espaces de porosité entre les univers religieux et parfois entre l'espace religieux et d'autres espaces et répertoires d'action totalement laïcisés, sociaux et politiques. Parler de pèlerinages 
inattendus revient donc à nous intéresser en premier lieu aux dynamiques d'hybridation religieuse à l'œuvre au sein de quelques pèlerinages conventionnels qui traduisent cependant la permanence et la persistance de formes de porosité interreligieuse au sein d'aires culturelles et géographiques pluralistes, mêlant des croyances et des symboles issus de différentes traditions confessionnelles. C'est là un phénomène ancien : que l'on songe par exemple au cas du Japon où, durant des siècles (et aujourd'hui encore), les cultes et les lieux sacrés shintoïstes et bouddhistes ont cohabité et parfois fusionné, donnant naissance à des systèmes syncrétiques comme le ryôbu shintô (shintô double). Ce phénomène a survécu même à la déclaration du shintô comme religion officielle en 1871 à travers les nouvelles religions qui mêlent pratiques shintoïstes et cosmogonie bouddhiste jusqu'à certaines expressions sectaires contemporaines où le bouddhisme japonais renoue avec l'hindouisme. Ce qui nous intéresse en l'espèce, ce n'est pas tant l'ancienneté de ces pratiques que leur persistance dans des pèlerinages contemporains. Plus près de nous, tel fut plus particulièrement le cas du bassin méditerranéen, l'un des espaces privilégiés où a pu se développer une telle mixité religieuse et où elle perdure aujourd'hui, dans sa partie orientale (Albera, Couroucli, 2009).

Le caractère "inattendu » de ces pèlerinages, d'hier comme d'aujourd'hui, renvoie également à la tentative plus ou moins artisanale de construction de nouvelles synergies interreligieuses autour de figures hagiographiques, de récits religieux ou de lieux symboliques atypiques qui mettent en scène des espaces de rencontres possibles entre croyants de fois différentes autour de l'invention de rites partagés combinant des formes religieuses plus ou moins exclusives, que l'histoire avait rendues réfractaires à d'autres modes d'accès au divin. Ces pèlerinages deviennent alors autant de témoignages discrets, presque intimistes, d'une unité différenciée. Ils témoignent en tout cas d'une inventivité religieuse qui entend relire de façon croisée et pacifiée les histoires religieuses des groupes et privilégier les figures et les récits de conciliation.

\section{Pèlerinages de contrebande}

Ces pèlerinages ont aussi en commun de se manifester selon un mode le plus souvent implicite, à la limite du non-dit, tant leur existence et leur signification dérangent les habitudes et les discours dominants. Le caractère inattendu de ces pèlerinages consiste donc dans le fait que leur énonciation en tant que tels ne va pas toujours de soi, car ils heurtent les certitudes religieuses, idéologiques, voire académiques, pour lesquelles existeraient des religions totalement homogènes, immuables, impénétrables à toute altérité, et bousculent des acceptions précises, sinon officielles, de celles-ci (comme d'ailleurs du vocable de pèlerinage luimême) répondant à un usage unique et exclusif et à une histoire incomparable. 
S'interroger comme nous le faisons sur des expressions atypiques de pèlerinage consiste également à soulever clairement la question de la récupération, de la redistribution ou du recyclage inconscient de la figure du pèlerinage au sein de groupes religieux qui, historiquement et doctrinalement, ont sévèrement réprouvé ce type de dévotion populaire. À la manière d’Henri Desroche (1974) qui s'interrogeait sur l'existence de "religions de contrebande » opposées aux religions et aux pouvoirs dominants, mais aussi sur la persistance de formulations et de schémas religieux dans des utopies et idéologies séculières (les socialismes). Il faut pouvoir s'interroger également sur des formes de pèlerinage de contrebande qui, bien que ne s'énonçant pas comme des pèlerinages religieux classiques, s’y apparentent sérieusement pour qui sait scruter les gestes, décortiquer les mises en scène et déceler l'indicible dans les rites collectifs qui fondent une communauté de valeurs et de souffrances partagées.

\section{Pèlerinages séculiers d'aujourd'hui}

On ne manquera pas également d'élargir cette analyse à ces autres pèlerinages hors normes que sont certaines formes de rassemblement de type séculier autour desquels s'agrègent des groupements idéologiques disparates (franc-maçonnerie libérale, mouvement ouvrier, libre pensée...), mais qui ont en partage un même idéal radical de justice sociale et font du rejet de toute expression religieuse l'autre pilier de leur credo militant. La part d'inattendu dans ces pèlerinages se manifeste alors dans l'entrecroisement des registres de l'action pèlerine avec l'agir politique et les réappropriations séculières auxquels ils donnent lieu de la part d'opérateurs extérieurs au champ religieux. C'est souvent au travers de rassemblements mémoriels et à l'occasion de parcours processionnels vers des lieux historiques éminents que transparaissent des traits majeurs de l'agir pèlerin comme la quête collective d'un "ailleurs" aux dimensions d'une république universelle où règnerait la justice sociale et autour de laquelle se fédère une société fraternelle de salut commun. La tension eschatologique est elle-même implicitement présente, comme l'énonçait le célèbre chant révolutionnaire d'Eugène Pottier, l'Internationale: "Debout les damnés de la terre, debout les forçats de la faim, la raison tonne en son cratère, c'est l'irruption de la fin (...) décrétons le salut commun (...) ! ». La figure plus ou moins métaphorique du pèlerinage est enfin abondamment présente dans des propositions d'itinéraires touristiques et de cheminements spirituels, nouveaux produits phares de l'ultramodernité.

Brouillage ou extrême fluidité des repères religieux, au revers des orthodoxies, reproduction de formes de rituels religieux dans des rassemblements profanes, ou slogan commercial pour touristes en mal d'émotions religieuses, ces déclinaisons de l'inattendu interrogent les formes contemporaines des pèlerinages et nous invitent à nous défendre de toute définition trop restrictive de ceux-ci. C'était une mise en garde que nous adressait Alphonse Dupront lorsqu'il déclarait 
" [qu']il ne saurait y avoir du fait pèlerin une définition globalisante close ; sa réalité phénoménale est celle d'une création assumée »(Dupront, 1987 : 41), et sans cesse renouvelée.

Ce dossier s'articule sur cinq articles, choisis parmi une vingtaine de communications présentées à l'occasion du colloque organisé par le CHERPA (Institut d'Études politiques d'Aix-en-Provence) en partenariat et avec le soutien de la Ville de Lourdes du 17 au 19 septembre 2008 sur "Les pèlerinages : parcours historiques, parcours croyants, parcours géographiques ", dont l'idée revient à Bernadette Camhi-Rayer, sociologue, doctorante du CHERPA, qui achève une thèse sur le pèlerinage. Qu'elle en soit ici remerciée.

Un premier article se propose d'aborder la transgression de l'unidimensionnalité religieuse des pèlerinages. Dionigi Albera évoque dans sa contribution l'existence traditionnelle dans le bassin méditerranéen de sites pèlerins où les religions et les univers de croyances se croisent et s'articulent. Ainsi, à côté des formes religieuses instituées et fortement encadrées, ces pèlerinages expriment et révèlent les formes populaires de religiosité qui empruntent aux ressources symboliques et religieuses présentes dans l'environnement social, sans aucune exclusivité.

À cette première expression d'un interreligieux "insoumis », on pourra opposer un interreligieux "prescrit ", comme c'est le cas dans la contribution de Manoël Pénicaud centrée sur l'invention du pèlerinage breton islamo-chrétien des Sept Dormants, conçu pour le rassemblement des fidèles chrétiens (catholiques) et des musulmans et dont Louis Massignon fut le premier inspirateur.

Hybridation maximale ou ultime transgression, le développement de formes pèlerines au sein de systèmes religieux et idéologiques a priori exclusifs de ce type de pratiques a également retenu notre attention et aiguisé notre souci de conduire un comparatisme que l'on pourra juger audacieux, sinon téméraire. C'est le cas de la contribution originale de Patrick Cabanel qui qualifie d' « impensable pèlerinage » l'assemblée annuelle protestante du Musée du Désert.

Une perspective peut-être elle aussi iconoclaste se retrouve dans notre propre contribution sur l'étude d'un pèlerinage laïque partisan, les commémorations annuelles devant le Mur des Fédérés du Père-Lachaise en souvenir des communards tombés sous les balles des troupes versaillaises, haut lieu de la mémoire du mouvement ouvrier, d'une gauche socialiste et libertaire et de la franc-maçonnerie progressiste et humaniste, dont le Grand Orient de France est le porte-drapeau.

Franck FRÉGOSI

UMR 7012 PRISME (Université de Strasbourg) - IEP Aix-en-Provence franck.fregosi@orange.fr 


\section{Bibliographie}

Albera Dionigi, Couroucli Maria, 2009, Religions traversées, Arles, Actes Sud/MMSH. Aubin-Boltanski Emma, 2007, Pèlerinages et nationalisme en Palestine. Prophètes, héros et ancêtres, Paris, Éditions de l'EHESS.

Boutry Philippe, Fabre Pierre Antoine, Julia Dominique, 2000, Rendre ses vœux, Paris, Éditions de l'EHESS.

Chélini Jean, Branthomme Henri, 2004, Les pèlerinages dans le Monde. À travers le temps et l'espace, Paris, Hachette.

Claverie Élisabeth, 2003, Les guerres de la vierge. Une anthropologie des apparitions, Paris, Gallimard.

Collectif, 1960, Les pèlerinages. Égypte ancienne, Israël, Islam, Inde, Perse, Tibet, Indonésie, Chine, Japon, Madagascar, Paris, Seuil, coll. "Sources orientales".

Desroches Henri, 1974, Les religions de contrebande, Paris, Mame.

Dupront Alphonse, 1987, Du sacré. Croisades et pèlerinages. Images et langages, Paris, Gallimard.

Zola Émile, 1894, Lourdes, Paris, G. Charpentier et E. Fasquelle Éditeurs. 